Original Research Article

\title{
Study of hearing impairment among "At risk" neonates by screening with OAE
}

\author{
Chithambaram N. S. ${ }^{1}$, Vijayakumar P. ${ }^{2}$ \\ ${ }^{1}$ Dr. N.S Chithambaram, ${ }^{2}$ Dr. P. Vijayakumar, both authors are affiliated with Department of Pediatrics, Vydehi Institute \\ of Medical Sciences \& Research Centre, Bangalore, India.
}

Corresponding Author: Dr. N.S. Chithambaram, Professor, Department of Pediatrics, PESIMSR, Kuppam, Andhra Pradesh, India. E-mail: chithams1@gmail.com

\begin{abstract}
Background: Hearing is one of the very important five senses. Normal speech and language development depend upon a child's ability to hear spoken language. Universal hearing screening is implemented in many developed countries. However, neither universal screening, nor high risk screening, exists in India. In India various studies have been conducted to detect the hearing loss on high risk neonates. Screening only the high-risk neonates can detect $50 \%$ of babies with hearing loss. Hence a mandatory hearing screening is needed to detect all such babies. Methods: A cross sectional study of 75 "At risk" babies were done. Babies underwent hearing screening after 48 hours of birth or before discharge from hospital using DPOAE test as the first level of screening. Babies who got "Refer" results were subjected to repeat testing with DPOAE after one month. Babies who got "Refer" results in the second screening test were referred for diagnostic test BERA to assess hearing loss. Data was analysed by appropriate statistical methodology. Results: Incidence of hearing loss among at risk babies is $2.6 \%$ (2/75). Both babies who had hearing loss had multiple risk factors and had bilateral hearing loss. Common risk factors observed are NICU care $>5$ days $100 \%(2 / 2)$, Ventilated baby $50 \%$ $(1 / 2)$, Preterm $100 \%(2 / 2)$, low birth weight $50 \%(1 / 2)$, jaundice requiring phototherapy $100 \%(2 / 2)$. Conclusion: Hearing loss is more common in "At risk" babies. Major risk factors are NICU admission, Preterm, LBW, Ventilated babies, and jaundice. It is necessary to implement neonatal hearing screening of at least "At risk" neonates in our country to secure normal, social and holistic development of the child. Two-stage DPOAE/BERA hearing screening is an efficient and cost-effective method for early detection of hearing impairment on a large scale.
\end{abstract}

Keywords: Audiometry, Evoked Response, Hearing loss, New born hearing screening, Otoacoustic Emissions.

\section{Introduction}

Hearing is one of the very important five senses. Normal speech and language development depend upon a child's ability to hear spoken language. Early infancy is the most appropriate time for a child to acquire the foundation of language and communication. Therefore, it is important to find out any problem in hearing early in life so that early intervention can be given to have normal language development [1].

Around 360 million people - 5\% of the world's population - live with hearing loss which is considered disabling; of these, nearly 32 million are children. The vast majority live in the world's low-income and middle-income countries. The World Health

Manuscript received: $10^{\text {th }}$ August 2019

Reviewed: $20^{\text {th }}$ August 2019

Author Corrected: $27^{\text {th }}$ August 2019

Accepted for Publication: $31^{\text {st }}$ August 2019
Organization (WHO) estimates that around $60 \%$ of childhood hearing loss could be avoided through prevention measures. When unavoidable, interventions are needed to ensure that children reach their full potential through rehabilitation, education and empowerment. Action is needed on both fronts [2].

Hearing impairment in infants should be identified as early as possible to enable interventions to take full advantage of the plasticity of developing sensory system.

All infants with confirmed permanent hearing loss receive services before 6 months of age in interdisciplinary intervention programs that recognize and build on strengths, informed choice, traditions, and cultural beliefs of the family [3]. 


\section{Original Research Article}

In India, the concept of universal hearing screening does not exist even in high risk babies leave alone normal new-borns.

There are some studies done in India to detect the hearing loss on high risk neonates in very few places.

Hence a Hearing screening program is needed to detect hearing loss among "At risk" new-born babies is needed, and it is the cost-effective approach in developing countries like India.

The recommended hearing screening techniques are either otoacoustic emissions (OAE) testing or auditory brainstem evoked responses (ABRs).

OAE tests, used successfully in most universal newborn screening programs, are quick, easy to administer, and inexpensive, and they provide a sensitive indication of the presence of hearing loss [4].

Hence this study was undertaken to evaluate the burden of hearing impairment among "At risk" neonates born in a tertiary care center by screening with OAE test and to look at the implementation of a hearing screening program in India.

\section{Materials and Methods}

Source of data: The source of data for the study are at risk neonates born in VIMS \& RC Hospital, Bangalore from Jan 2016 to June 2017. At risk criteria is defined by HRR of JCIH $2007^{9}$ Position Statement.

Duration of study: Eighteen months.

Study design: A Cross Sectional study.
Sample size: Assuming a population prevalence of $10 \%$ "A risk" neonates ${ }^{10}$ [with hearing impairment of $2 \%{ }^{4}$ ] at an alpha value of $5 \%$, with a power of $80 \%$, with an absolute precision of $5 \%$, a minimum of $\mathbf{7 5}$ subjects in "At risk" group have been calculated.

Inclusion criteria: The study includes "At risk" Neonates born in VIMS \& RC Hospital during the study period. 75 "At risk" neonates as per JCIH 2007 statement were included in this study.

Exclusion criteria: Neonates whose parent/ guardian not willing for Screening test. Neonates whose parent/ guardian not willing for further follow up if the screening test gives REFER result.

Method of collection of data: Babies born in VIMS \& RC Hospital who fulfil the inclusion and exclusion criteria were included for study. Informed written consent was obtained from parents prior to the study.

All the "At risk" babies underwent hearing assessment after 48 hours of birth or before discharge from hospital using Distortion Product Oto Acoustic Emission [DPOAE] test using a GSI Audera System as the first level of screening.

The test will give a PASS or REFER result. Neonates who get REFER result in the initial screening will be subjected to second screening with DPOAE after one month.

Infants who get REFER results in the screening test twice will be referred for further evaluation by BERA to assess hearing loss.

\section{Results}

A total of 75 "At risk" neonates were included into the study during the study period. Risk factors for hearing impairment are as per High risk registry of JCIH 2007 (at risk group).

In the present study of 75 "At risk" neonates 46.7\% (35) were female and 53.3\% (40) were male as shown in Table 1 . Out of 75 "At risk" neonates $94.7 \%$ (71) were non consanguineous and 5.3\% (4) were consanguineous, $4 \%(3)$ were of second degree, $1.3 \%$ (1) was of third degree, $45.3 \%$ (34) were of term gestation and $54.6 \%$ (41) were Preterm, 25.3\% (19) were of $28-32$ weeks, $29.3 \%$ ( 22) were of 32-37 weeks).52\% (39) out of 75 were delivered by LSCS and $48 \%$ (36) were delivered by Vaginal delivery.

Of the 75 "At risk" neonates $18.7 \%$ (14) were of birth weight $<1.5 \mathrm{~kg}, 38.7 \%$ (29) were of 1.5 to $2.49 \mathrm{~kg}, 42.7 \%$ (42) were of $\geq 2 \mathrm{~kg}$. Out of 75 at risk neonates $26.6 \%(20)$ had maternal history of miscarriages.

But none of the neonates studied had maternal history of viral infections or exposure to $\mathrm{X}$ ray or use of teratogenic medications. 
Table-1: Characteristics of neonates.

\begin{tabular}{|c|c|c|}
\hline Characteristics of neonates & & At Risk \\
\hline \multirow{2}{*}{ Gender } & Female & $35(46.7 \%)$ \\
\hline & Male & $40(53.3 \%)$ \\
\hline \multirow{5}{*}{ Consanguinity } & $\mathrm{NCM}$ & $71(94.7 \%)$ \\
\hline & $\mathrm{CM}$ & $4(5.3 \%)$ \\
\hline & 1 & $0(0 \%)$ \\
\hline & 2 & $3(4 \%)$ \\
\hline & 3 & $1(1.3 \%)$ \\
\hline \multirow{4}{*}{$\begin{array}{l}\text { Gestational age } \\
\text { (in weeks) }\end{array}$} & Term & $34(45.3 \%)$ \\
\hline & $<28$ & $0(0 \%)$ \\
\hline & $28-32$ & $19(25.3 \%)$ \\
\hline & $32-37$ & $22(29.3 \%)$ \\
\hline \multirow{2}{*}{ Mode of delivery } & $\mathrm{CS}$ & $39(52 \%)$ \\
\hline & VD & $36(48 \%)$ \\
\hline \multirow{3}{*}{ Birth weight (in kg) } & $<1.5$ & $14(18.7 \%)$ \\
\hline & $1.5-2.49$ & $29(38.7 \%)$ \\
\hline & $\geq 2.5$ & $32(42.7 \%)$ \\
\hline \multirow{4}{*}{ Maternal history } & Miscarriages & $20(26.6 \%)$ \\
\hline & Viral infections & $0(0 \%)$ \\
\hline & X ray & $0(0 \%)$ \\
\hline & Medication & $0(0 \%)$ \\
\hline
\end{tabular}

Table-2: Risk factors/possible risk factors.

\begin{tabular}{|l|c|c|}
\hline \multicolumn{1}{|c|}{ Risk factors/possible risk factor } & At risk $(\mathbf{n = 7 5 )}$ & P value \\
\hline NICU care $>$ 5days & $75(100 \%)$ & $<0.001^{* *}$ \\
\hline Ventilated & Ventilated & $<0.001^{* *}$ \\
\hline Preterm & Preterm & $<0.001^{* *}$ \\
\hline Low birth weight & Low birth weight & $<0.001^{* *}$ \\
\hline Ototoxic medication used & 0 & - \\
\hline Sepsis & $7(9.3 \%)$ & $<0.001^{* *}$ \\
\hline Meningitis & 0 & - \\
\hline Syndromic & $1(1.3 \%)$ & $0.083+$ \\
\hline Jaundice requiring exchange transfusion & 0 & - \\
\hline Jaundice requiring phototherapy & $68(90.6 \%)$ & $<0.001^{* *}$ \\
\hline
\end{tabular}

Out of the various risk factors in the present study, $100 \%$ of babies had NICU stay of more than 5 days, $41 \%$ were preterm, $42 \%$ were low births, $68 \%$ had jaundice requiring phototherapy, $13.3 \%$ were ventilated and $9.3 \%$ had sepsis. All the above risk factors had $\mathrm{P}$ value $<0.001$ which were significant.

"At risk" group was defined according to JCIH 2007 Positional statement. Jaundice requiring phototherapy is not included in JCIH 2007 Positional statement, but since it is a possible risk factor those babies requiring phototherapy were included in the present study. 
Table-3: $1^{\text {st }}$ Screening of "at risk" patients.

\begin{tabular}{|c|c|c|}
\hline Screening 1 & At risk $(\mathbf{n}=\mathbf{7 5})$ & P value \\
\hline B/L Pass & $46(61.3 \%)$ & $<0.001 * *$ \\
\hline B/L Refer & $16(21.3 \%)$ & $<0.001 * *$ \\
\hline Only right ear refer & $5(6.6 \%)$ & 0.343 \\
\hline Only left ear refer & $8(10.6 \%)$ & $0.062+$ \\
\hline
\end{tabular}

Results of Screening-1:Out of 75 "At risk" neonates screened by OAE 61.3\% (46) had pass results in both ears, $21.3 \%$ (16) had refer results in both ears , 6.6\%(5) had refer results only in right ear and , 10.6\%( 8 ) had refer results only in left ear as shown in Table 3 .

Table-4: $2^{\text {nd }}$ Screening of "At risk" patients who had Refer in $1^{\text {st }}$ Screening

\begin{tabular}{|c|c|c|}
\hline Screening 2 & At risk $(\mathbf{n}=\mathbf{2 9})$ & P value \\
\hline B/L Pass & $25(86.2 \%)$ & 0.128 \\
\hline B/L Refer & $2(6.9 \%)$ & 0.500 \\
\hline Only right ear refer & $1(3.4 \%)$ & 1.000 \\
\hline Only left ear refer & $1(3.4 \%)$ & 1.000 \\
\hline
\end{tabular}

Results of Screening-2:Out of 29 "At risk" neonates who underwent second screening by OAE 86.2\% (25) had "Pass" results in both ears, 6.9\% (2) had "Refer" results in both ears , 3.4\%(1) had "Refer" results only in right ear and 3.4\%( 1) had "Refer" results only in left ear as shown in Table 4.

Table-5: BERA distribution of patients "At risk" neonates

\begin{tabular}{|c|c|c|}
\hline BERA & "At risk" & P value \\
\hline Total tested & $4(5.3 \%)$ & $<0.001 * *$ \\
\hline B/L Hearing loss & $2(2.6 \%)$ & $0.014^{*}$ \\
\hline B/L Normal & $2(2.6 \%)$ & $0.014 *$ \\
\hline
\end{tabular}

Diagnostic test (BERA) Results: Out of 4 "At risk" neonates who underwent diagnostic test, BERA 50\% (2) had normal hearing sensitivity and 50\% (2) had hearing loss. In other words $2.6 \%$ (2) of the total 75 "At risk" neonates screened had confirmed hearing loss. Both the neonates had bilateral loss.

Table-6: Total Results

\begin{tabular}{|c|c|c|c|c|c|c|}
\hline & $\begin{array}{c}\text { Babies } \\
\text { screened }\end{array}$ & $\begin{array}{c}\text { Babies } \\
\text { referred on } \\
\text { screening-1 }\end{array}$ & $\begin{array}{c}\text { Babies who } \\
\text { underwent } \\
\text { screening-2 }\end{array}$ & $\begin{array}{c}\text { Babies } \\
\text { referred on } \\
\text { screening-2 }\end{array}$ & $\begin{array}{c}\text { Babies who } \\
\text { underwent } \\
\text { diagnostic } \\
\text { BERA }\end{array}$ & $\begin{array}{c}\text { Babies with } \\
\text { confirmed } \\
\text { hearing } \\
\text { loss }\end{array}$ \\
\hline "At risk" & $75(100 \%)$ & $29(38.6 \%)$ & $29(38.6 \%)$ & $4(5.3 \%)$ & $4(5.3 \%)$ & $2(2.66 \%)$ \\
\hline
\end{tabular}

$\mathrm{P}<0.001^{* *}$, Significant

Results of the whole screening: A total of 75 "At risk" neonates were studied.29 neonates got referred in first screening. All these 29 neonates underwent second screening. 4 out of 29 "At risk" neonates got "Refer" results in second screening also. All these 4 "At risk" neonates underwent diagnostic test i.e. BERA. 2 of them had normal hearing sensitivity and 2 of them had confirmed hearing loss. 


\section{Discussion}

In this two staged New-borns Hearing screening conducted by us, incidence of hearing loss among "At risk" neonates is $2.6 \%(2 / 75)$. Result of the present study is in par with results of previous studies. In a cross-sectional study conducted by Amit Kumar et al. at BJMC Hospital Ahmadabad, incidence of hearing loss among all neonates screened was $2.2 \%$ (11/500). Incidence among "At risk" neonates was $10 \%(11 / 110)$. In another descriptive study conducted by Ann Mary Augustine et al. at CMC Vellore [5] incidence of hearing loss among all neonates screened was $0.41 \%$ (39/9448). Incidence among "At risk" neonates was $0.34 \%(8 / 2339)$.

In a study conducted by John Jewel et al. prospectively on all neonates born in Christian Medical College and Hospital, Ludhiana [6] incidence of hearing loss among all neonates screened was $0.4 \%$ (4/1000). In a prospective study of a non-randomized cohort of 1769 neonates conducted by Nagapoornima et al at St John's Medical College hospital [7], incidence of hearing loss among all neonates screened was $0.56 \%$ (10/1769).

Incidence among "At risk" neonates was 1\% (3/279). Another study done by Abraham K Paul in Cochin, Kerala [8], incidence of hearing loss among all neonates screened was $0.28 \%(29 / 10165)$. Incidence among "At risk" neonates was 1\% (21/2031).

In a study done by Ohl c et al in France, 1461 "At risk" infants were screened, $4.55 \%$ were diagnosed as deaf or hard for hearing. The risk factors for sensorineural hearing loss were (in order of statistical significance): severe birth asphyxia; neurological disorder; syndromes known to be associated with hearing loss; TORCH (toxoplasmosis, rubella, cytomegalovirus, herpes) infections; family history of deafness; age at the time of screening; and the association of 2 or more risk factors [9].

In a study done by Van Riper et al, 2,103 "At risk" new-borns were screened, One hundred fourteen (5.4\%) infants were diagnosed with bilateral hearing loss. 23 infants $(1 \%)$ presented with unilateral hearing loss. 67 (49\%) of the 137 infants diagnosed with hearing loss presented with greater than moderate hearing loss. 9 $(13.4 \%)$ of these 67 patients presented with delayed onset hearing loss that was diagnosed at appointments subsequent to the initial screening. The largest percentage of diagnosed hearing loss was found in the "craniofacial anomalies" category [10]
In a study done by Botelho et al in Brazil 188 newborns were evaluated using evoked otoacoustic emissions and distortion product and auditory behaviour. Of 188 children two (1.1\%) were excluded, and 174 (92.6\%) had results within normal limits. Hearing impairment was found in 12 children $(6.3 \%)$; hearing loss was retrocochlear in three infants $(25 \%)$. Unilateral hearing loss was present in two infants $(16.7 \%)$; bilateral hearing loss was present in 10 infants $(83.3 \%)$ [11].

In study done by Eden et al Of 5,215 live births in Christchurch, 564 infants were discharged through the neonatal intensive care unit. Of these, 86 had risk factors for sensorineural hearing loss. There were 72 $(84 \%)$ infants tested at audiology, with fifteen $(17 \%)$ having abnormal test results [12].

In the present study out of the 2 neonates who had hearing loss both of them had multiple risk factors and had bilateral hearing loss. One baby had 5 risk factors and other had 3 risk factors. Common risk factors observed in the present study are NICU care $>5$ days $100 \%(2 / 2)$, Ventilated baby 50\% (1/2), Preterm 100\% $(2 / 2)$, low birth weight $50 \%(1 / 2)$, jaundice requiring phototherapy $100 \%(2 / 2)$ which is in par with previous results.

Along with the well-known risk factors of HRR of JCIH 2007 [13], a strong association between other risk factors and hearing impairment could not be established due to small sample size, warranting a detailed study of these other possible risk factor for congenital hearing impairment. The identification of local risk factors and addition of them into high risk registry can improve the outcome and efficiency of target screening in resource poor nation like India.

It is necessary and high time to implement and incorporate a mandatory neonatal hearing screening program if not a Universal neonatal Hearing screening program in our country to secure normal, social and holistic development of the child by detecting hearing loss at birth and providing remedial services at the earliest. National policies in these lines have to be made for neonatal hearing screening in all national health care facilities in India. Mandatory new-born hearing screening of "At risk" neonates can yield high returns, and the 2-staged hearing screening program is cost effective and feasible. A child who receives early interventions for hearing loss requires less expensive special education in later part of life and has a better 


\section{Original Research Article}

chance to have a normal social life and improved quality of life [14].

\section{Limitations of the study}

1.Small sample size.

2.Specific cause -effect relationship could not be established.

\section{Conclusion}

It can be safely concluded from the present study that hearing loss is more common in those babies with risk factors and there is a relationship between having risk factor (s) for hearing loss, not passing a hearing screen, and then later having a confirmed hearing loss. Major risk factors are NICU admission, Preterm, LBW, Ventilated babies, and jaundice.

This study has shown that two-stage TEOAE/DPOAE hearing screening can be successfully implemented as new-borns hearing screening method for early detection of hearing impaired, on a large scale, in a tertiary care hospital to achieve high-quality standard of screening programs. The finding is consistent with previous researches. As the incidence of hearing impairment in "At risk" new-borns is higher than the "no risk" newborns, Neonatal hearing screening of at least 'At risk' neonates is essential to detect large number of hearing impairment in the susceptible 'At risk 'new-borns population.

\section{What this study adds to the existing knowledge?}

Two-stage TEOAE/DPOAE hearing screening can be successfully implemented as new-borns hearing screening method. Hearing screening of at least 'At risk' neonates is essential to detect large number of hearing impairment.

\section{Author's contributors}

Dr. N. S. Chithambaram conceptualized the study, designed the study protocol, reviewed the literature and revised the manuscript; Both the authors approved the final version of the manuscript, and are willing to be accountable for all aspects of the study.Dr. N. S. Chithambaram shall act as guarantor of the paper.

Dr. P. Vijayakumar collected the data, reviewed the literature and drafted the first version of the manuscript.

Funding: Nil, Conflict of interest: None initiated, Permission from IRB: Yes

\section{References}

1. Kumar A, Shah N, Patel KB, Vishwakarma R. Hearing screening in a tertiary care hospital in India. Journal of clinical and diagnostic research: JCDR. 2015; 9(3): MC01. doi.org/10.7860/JCDR/2015/11640. 5698

2. World Health Organization. Childhood hearing loss: Act now, here's how. World Health Organization; 2016.

3. Joint Committee on Infant Hearing. American Academy of Audiology, American Academy of Pediatrics, American Speech-Language-Hearing Association and Directors of Speech and Hearing Programs in State Health and Welfare Agencies: Year 2000 position statement: principles and guidelines for early hearing detection and intervention programs. Pediat. 2000;106:798-781

4. Kliegmassn RM, Stanton B, Geme JS, Schor NF, Behrman RE. Nelson textbook of pediatrics.

5. Augustine AM, Jana AK, Kuruvilla KA, Danda S, Lepcha A, Ebenezer J, et al. Neonatal hearing screening--experience from a tertiary care hospital in southern India. Indian Pediatr. 2014;51(3):179-183. doi:10.1007/s13312-014-0380-5

6. Jewel J, Varghese PV, Singh T, Varghese A. Newborn hearing screening-experience at a tertiary hospital in northwest India. Int J Otolaryngol Head Neck Surg. 2013;2 (05): 211.doi.org/10.4236/ijohns. 2013. 25044

7. Nagapoornima P, Ramesh A, Srilakshmi, Rao S, Patricia PL, Gore M, et al. Universal hearing screening. Indian J Pediat. 2007;74(6):545-549. doi: 10.1007/ s 12098-007-0105-z

8. Paul AK. Early identification of hearing loss and centralized newborn hearing screening facility-the Cochin experience. Indian Pediat. 2011;48(5):355-359. doi.org/ 10.1007/s13312-011-0067-0

9. Ohl C, Dornier L, Czajka C, Chobaut JC, Tavernier L. Newborn hearing screening on infants at risk. Int $\mathbf{J}$ Pediatr Otorhinolaryngol. 2009;73(12):1691-1695. doi: 0.1016/j.ijporl.2009.08.027. Epub 2009 Sep 30.

10. Van Riper LA, Kileny PR. ABR hearing screening for high-risk infants. Am J Otol. 1999;20(4):516-521. 
11. Botelho FA, Bouzada MC, Resende LM, Silva CF, Oliveira EA. Prevalence of hearing impairment in children at risk. Braz J Otorhinolaryngol. 2010; 76(6): 739-744. doi:https://doi.org/10.1590/S1808-869420100 00600012

12. Eden D, Ford RP, Hunter MF, Malpas TJ, Darlow B, Gourley J. Audiological screening of neonatal intensive care unit graduates at high risk of sensorineural hearing loss. NZ Med J. 2000;113 (1110): 182-183.
13. Joint Committee on Infant Hearing. Year 2007 Position Statement: Principles and Guidelines for Early Hearing Detection and Intervention Programs. Pediat. 2007;120(4):898-921. doi: https://doi.org/10.1542/peds. 2007-2333

14. Newborn and infant hearing screening. World Health Organization 2009:1-39. https://www.who. int/ blindness/publications/Newborn_and_Infant_Hearing_S creening_Report.pdf?ua $=1$

\section{How to cite this article?}

Chithambaram N. S, Vijayakumar P. Study of hearing impairment among “At risk" neonates by screening with OAE. Int J Pediatr Res. 2019;6(08):429-435.doi:10.17511/ijpr. 2019.i08.07 